Research Article

\title{
Phylogeographic history of South American populations of the silky anteater Cyclopes didactylus (Pilosa: Cyclopedidae)
}

\author{
Raphael Teodoro Franciscani Coimbra, Flávia Regina Miranda, Camila Clozato Lara, \\ Marco Antônio Alves Schetino and Fabrício Rodrigues dos Santos \\ Laboratório de Biodiversidade e Evolução Molecular, Departamento de Biologia Geral, \\ Instituto de Ciências Biológicas, Universidade Federal de Minas Gerais, Belo Horizonte, MG, Brazil.
}

\begin{abstract}
Cyclopes didactylus, commonly called silky anteater, is the smallest and least studied of the anteaters. It is an arboreal species occurring in rainforests, ranging from southern Mexico to Central and South America, with an apparently disjoint distribution between Amazon and Atlantic rainforests in Brazil. Although seven subspecies are recognized, little is known about its geographical variation. Thus, to evaluate the population dynamics and evolutionary history of the South American silky anteater, we analyzed 1542 bp sequences of the mitochondrial control region (CR), COI and $C y t-b$ genes of 32 individuals. Haplotype network, AMOVA and molecular dating analyses were performed and identified seven geographic clusters. The split of lineages separating Cyclopedidae (Cyclopes) and Myrmecophagidae (Myrmecophaga and Tamandua genera) was estimated around 41 million years ago (mya), and the intraspecific lineage diversification of $C$. didactylus began in the Miocene around 13.5 mya, likely in southwestern Amazonia. Tectonic and climatic events that took place in South America during the Tertiary and Quaternary seem to have influenced the evolutionary history of the species at different levels. This is the first study to investigate the population dynamics and phylogeography of the silky anteater, which contributes to a better comprehension of the biogeography of South America.
\end{abstract}

Keywords: Xenarthra, mitochondrial DNA, population structure, molecular dating, South America.

Received: February 22, 2016; Accepted: October 3, 2016.

\section{Introduction}

Cyclopes didactylus, commonly called silky anteater, is the only living species of the Cyclopedidae family and the smallest of all known anteaters with adults averaging $430 \mathrm{~mm}$ long and $235 \mathrm{~g}$ of weight (Gardner, 2007). It has nocturnal habits and appears to be completely arboreal (Montgomery, 1985). This species exhibits a "dense, woolly to silky, silvery-gray to golden-brown body pelage, two digits on the manus and four on the pes, a prehensile tail" (Gardner, 2007) and a "hind feet highly modified for grasping small twigs while climbing and feeding" (Wetzel, 1985).

The silky anteater inhabits tropical rainforests, ranging from southern Mexico to Central and South America, and is apparently disjoint between Amazon and Atlantic rainforests in Brazil (Figure 1; Gardner, 2007). In South America it occurs in the northern Andean valleys of Colombia, in the west of the Andes along the Pacific coast

Send correspondence to Fabrício R. Santos. Laboratório de Biodiversidade e Evolução Molecular, Departamento de Biologia Geral, Instituto de Ciências Biológicas, Universidade Federal de Minas Gerais, Av. Antônio Carlos, 6627 P.O.box 486, 31270-010 Belo Horizonte, Minas Gerais, Brazil. E-mail: fsantos@ icb.ufmg.br. lowlands of Colombia and Ecuador, in the rainforests of Venezuela and Guianas, and southwards into the Amazon basin drainage of the lowlands of Colombia, Ecuador, Peru, Brazil and Bolivia (Gardner, 2007; Miranda and Superina, 2010; Superina et al., 2010). The Atlantic Forest of the northeastern coast of Brazil harbors a small and apparently isolated population, ranging from the states of Rio Grande do Norte to Alagoas (Miranda and Superina, 2010). Considering its wide distribution, little is known of its geographical variation (Aguiar and Fonseca, 2008).

Seven subspecies of the silky anteater are currently recognized, which is based mainly on coat color and the presence of darker dorsal, sternal or ventral stripes (Wetzel, 1982; Gardner, 2007; Hayssen et al., 2012). Among them, C. d. mexicanus is the only one that does not occur in South America, while $C . d$. dorsalis is present mainly in Central America but also occurs in northern and northwestern Colombia (Wetzel, 1982; Gardner, 2007; Hayssen et al., 2012). The last subspecies found in the west of the Andes is C. d. eva, which occurs in the Pacific coast lowlands of Colombia and Ecuador (Wetzel, 1982; Gardner, 2007; Hayssen et al., 2012). All the other subspecies are located in the east of the Andean Cordillera including $C . d$. didactylus, which is present from Venezuela through 


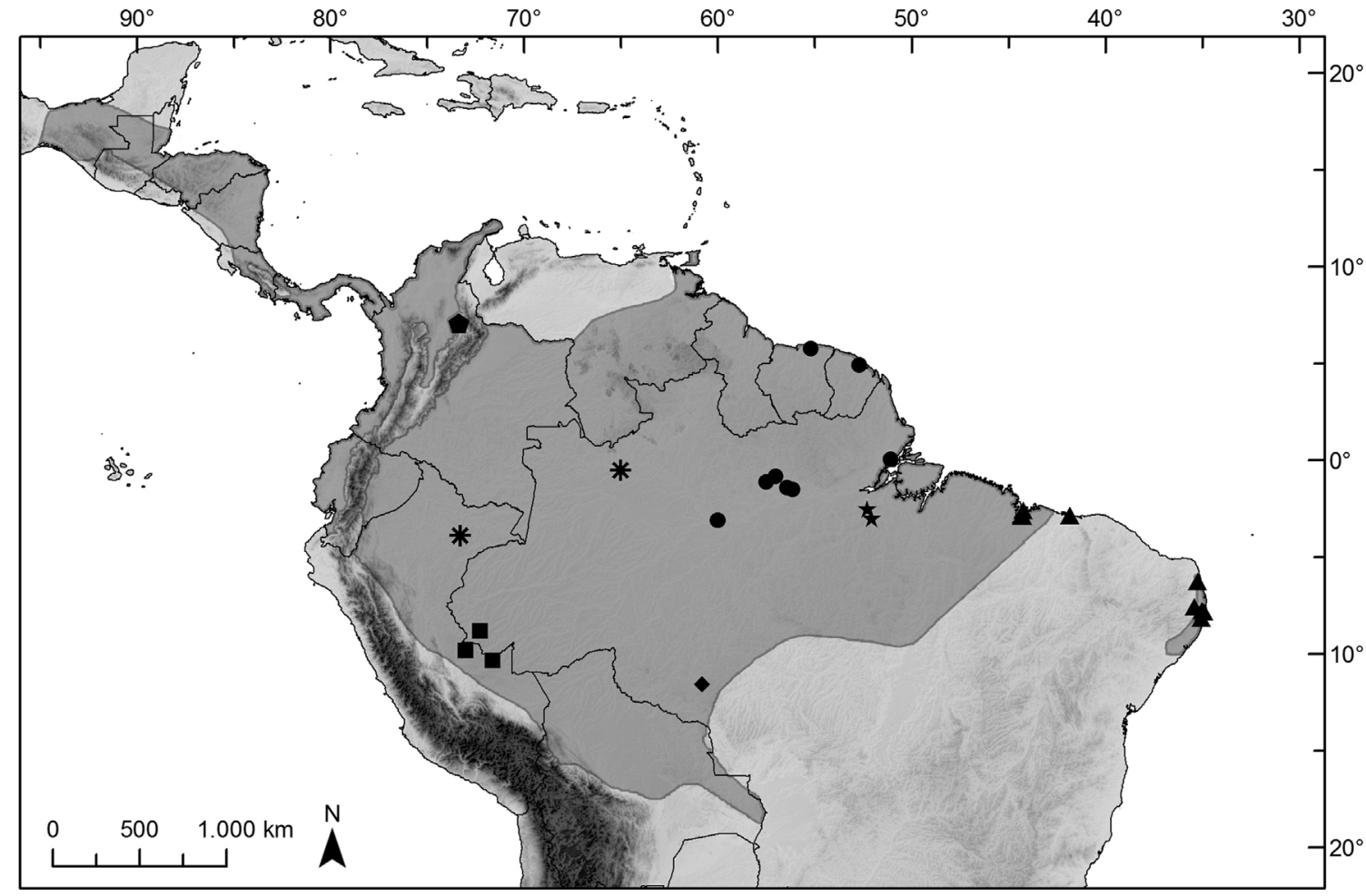

Figure 1 - Map of Cyclopes didactylus range and sampling localities. Species distribution based on Superina et al. (2010). Different symbols mark localities of each geographic clusters. Square $=\mathrm{UA}$; diamond $=\mathrm{RO}$; asterisk $=\mathrm{LS} ; \mathrm{star}=\mathrm{PV}$; pentagon $=\mathrm{CWA}$; circle $=\mathrm{MOSF}$; and triangle $=\mathrm{NB}$.

Guianas and in northeastern Brazil; C. d. melini, occurring in the northern Amazon basin of Brazil and adjoining Venezuela and Colombia; $C$. $d$. ida, which is found throughout the western Amazon basin; and C.d. catellus, occurring in southeastern Peru, northeastern Bolivia and central Amazon basin (Wetzel, 1982; Gardner, 2007; Hayssen et al., 2012).

There is no fossil record for the silky anteater (McDonald et al., 2008), but Palaeomyrmidon incomptus, a fossil taxon from the Huayquerian period (9-6.8 mya), is considered its sister group (Hirschfeld, 1976; Gaudin and Branham, 1998). Moreover, Delsuc et al. (2004, 2012), based on the analysis of nuclear and mitochondrial data from all living xenarthran genera, estimated the divergence between Cyclopedidae (Cyclopes) and Myrmecophagidae (Myrmecophaga and Tamandua genera) at around 40 and 45.5 mya (middle Eocene), respectively. However, a more recent estimate by Gibb et al. (2016) that used complete mitogenomes from all living xenarthran species set it at ca. 37.8 mya.

Home to the origin and diversification of all xenarthran species (Patterson and Pascual, 1972), the South American continent has undergone several geological changes during the Tertiary and Quaternary. Major phases of Andean uplift started in the Paleocene and the most intense peaks of mountain building in the Northern and Central Andes took place in the last 30 million years (Sempere et al., 1990, 1994; Lundberg et al., 1998; Hoorn et al.,
2010; Antonelli and Sanmartín, 2011). Episodes of marine incursions from the Pacific (Lundberg et al., 1998; Antonelli et al., 2009), the Caribbean Sea (Hoorn, 1993; Lovejoy et al., 2006) and the Paraná River basin (Lundberg et al., 1998) were recorded from the Paleocene until the Miocene (Lovejoy et al., 2006). Periods of thermal optimum occurred in the early Eocene, late Oligocene and middle Miocene (Zachos et al., 2001) while global cooling trends were documented from middle Eocene to middle Oligocene and since the late Miocene (Zachos et al., 2001). The uplift of the Panama Isthmus triggered the Great American Biotic Interchange (GABI) by ca. 3.5 mya (Hoorn et al., 2010; Antonelli and Sanmartín, 2011). However, recent studies suggest a starting for dispersal pulses of the GABI as early as the Oligocene-Miocene transition (Bacon et al., 2015), and at least a partial closure of the Central American seaway by 13-15 mya (Montes et al., 2015). Finally, the Pleistocene glaciations started ca. 2.6 mya (Hoorn et al., 2010; Antonelli and Sanmartín, 2011), causing many changes in the South American rainforest distribution (Oliveira et al., 1999; Auler et al., 2004; Wang et al., 2004; Ortiz-Jaureguizar and Cladera, 2006). All these tectonic and climatic events during the Tertiary and Quaternary changed the landscapes on the continent and some of them were previously associated with synchronous diversification events in Xenarthra (Delsuc et al., 2004).

To date there is no genetic study regarding population structure and dynamics, and timing of intraspecific lineage 
diversification for the silky anteater. Here we present the first attempt, using three mitochondrial fragments, to assess the phylogeographic patterns and date the divergences of the South American populations of Cyclopes didactylus to compare them with environmental changes occurring in the continent at different times.

\section{Materials and Methods}

\section{Sample collection and DNA extraction}

Liver, muscle, blood or hair samples of 31 specimens of Cyclopes didactylus from the Peruvian Departments of Ucayali $(\mathrm{n}=2)$ and Loreto $(\mathrm{n}=2)$, Suriname $(\mathrm{n}=1)$, Colombia $(n=1)$ and the Brazilian States of Acre $(n=1)$, Amapá $(\mathrm{n}=1)$, Amazonas $(\mathrm{n}=5)$, Maranhão $(\mathrm{n}=3)$, Pará $(n=6)$, Pernambuco $(n=4)$, Piauí $(n=3$ - new occurrence record; F. R. Miranda, unpublished data), Rio Grande do Norte $(\mathrm{n}=1)$ and Rondônia $(\mathrm{n}=1)$ were collected since 2005 by the Institute of Research and Conservation of Anteaters in Brazil (Projeto Tamanduá) or obtained from other museums and institutions, and deposited at Laboratório de Biodiversidade e Evolução Molecular (LBEM) in Universidade Federal de Minas Gerais (UFMG), Brazil. The samples were preserved in $70 \%$ ethanol and the DNA extraction was performed, according to reagents availability, by a standard phenol-chloroform protocol (Sambrook and Russell, 2001) or using a DNeasy Blood \& Tissue Kit (QIAGEN) following the manufacturer's instructions. A sequence from a French Guiana individual was retrieved from GenBank (accession number KT818539) for some analyses. A map of sampling localities and a detailed list of samples are available in Figure 1 and Table S1, respectively.

\section{Amplification and sequencing}

Fragments of the mitochondrial control region (CR) and the Cytochrome c Oxidase subunit I (COI) and Cytochrome b $(C y t-b)$ genes were amplified with primers $\mathrm{L}_{0}$ [L15445] (Douzery and Randi, 1997) and $E_{3}$ [H15978] (Huchon et al., 2001), LCO1490 and HCO2198 (Folmer et al., 1994), and CytB-L = 5'-CCATGAGGACAAATATCATTCTGAGG-3' and CytB-H = 5'-TGGTTTACAAGACCAGTGTAAT-3' (previously designed by our laboratory), respectively. Amplification reactions were carried out in a final volume of $10 \mu \mathrm{L}$ containing $10 \mathrm{ng}$ of DNA, $1 \mathrm{x}$ reaction buffer (Invitrogen), $1.5 \mathrm{mM} \mathrm{MgCl}_{2}$ (Invitrogen), $100 \mu \mathrm{M}$ dNTPs, $0.2 \mu \mathrm{M}$ of each primer (forward and reverse), $0.5 \mathrm{mg} / \mathrm{mL}$ of BSA adjuvant and $0.2 \mathrm{U}$ of Platinum ${ }^{\circledR}$ Taq DNA Polymerase (Invitrogen). Cycling reactions consisted of an initial denaturation step of $94^{\circ} \mathrm{C}$ for $5 \mathrm{~min}$, followed by 35 cycles of $94{ }^{\circ} \mathrm{C}$ for $30 \mathrm{~s}, 50^{\circ} \mathrm{C}(\mathrm{COI}), 52^{\circ} \mathrm{C}(\mathrm{CR})$ or $53{ }^{\circ} \mathrm{C}(\mathrm{Cyt}-\mathrm{b})$ for $45 \mathrm{~s}, 72^{\circ} \mathrm{C}$ for $1 \mathrm{~min}$, and a final extension step of $72{ }^{\circ} \mathrm{C}$ for 10 min. Adjustments in PCR reagents and template DNA concentrations and in primers annealing temperatures were made when necessary. PCR efficiency was assessed by electrophoresis on $1 \%$ agarose gel and the amplicons were submitted to purification protocol by polyethylene glycol 20\% precipitation (described in Santos Júnior et al., 2015). Purified amplicons were sequenced in a MegaBACE 1000 DNA Sequencing System (AmershamBiosciences) or in an ABI 3130xl Genetic Analyzer (Applied Biosystems).

\section{Data analysis}

Consensus sequences were generated with Phred v. 0.20425 (Ewing and Green, 1998; Ewing et al., 1998), Phrap v. 0.990319 (Green, 1994-1999) and Consed 19.0 (Gordon et al., 1998) or SeqScape v. 2.6 (Applied Biosystems) and aligned in MEGA 7 (Kumar et al., 2016).

The concatenated sequences of the three mitochondrial fragments were used to construct a median-joining haplotype network (Bandelt et al., 1999) using the NETWORK 5 software (Fluxus Technology Ltd, 1999-2016) to visualize the relationships between haplotypes and their geographical distribution. Also an analysis of molecular variance (AMOVA; Excoffier et al., 1992) was performed in Arlequin v.3.5 (Excoffier and Lischer, 2010) to assess the distribution of genetic variability at different hierarchical levels. For the latter analysis, we included only the haplotype network clusters containing two or more samples and tested for significance with 10,000 permutations $(P<0.05)$.

To infer on the evolutionary history of the species, a molecular dating analysis was carried out using the BEAST 2.3 package (Bouckaert et al., 2014). In this analysis, CR sequences were not considered, and both $C O I$ and $C y t-b$ sequences were partitioned by codon position. The analysis was performed using the reversible-jump based substitution model (Bouckaert et al., 2013), allowing for gamma rate heterogeneity and invariant sites, and a relaxed clock log-normal model with a birth-death tree prior combined with soft fossil calibration constraints (Yang and Rannala, 2006). Calibration intervals for crown xenarthran nodes were based on Meredith et al. (2011) and are available in Table S2. Sequences of Myrmecophaga tridactyla (KT818549), Tamandua mexicana (KT818551), Tamandua tetradactyla (KT818552), Bradypus torquatus (KT818524), Choloepus didactylus (KT818537) and Dasypus kappleri (KT818541) retrieved from GenBank were used as outgroups. Three independent MCMC chains were run for 50,000,000 generations and sampled every 5,000 generations. Trace files were checked for chain convergence and sufficient effective sample sizes (ESS) in Tracer v. 1.6 (Rambaut et al., 2014) and the tree files were combined in LogCombiner with a 50\% burn-in. The maximum clade credibility (MCC) tree and the associated posterior probabilities and common ancestor heights were summarized with a $33 \%$ burn-in in TreeAnnotator from the 15,000 combined trees sampled from the three independent 
runs. BEAST 2.3 runs were carried out on CIPRES Science Gateway v.3.3 (Miller et al., 2010).

\section{Results}

\section{Sequencing}

CR sequences varied in length from 299 to $308 \mathrm{bp}$ due to indels (309 bp alignment; KU596973-KU597000), COI sequences of $555 \mathrm{bp}$ (KU597001-KU597027) and $C y t-b$ sequences of 678 bp (KU597028-KU597057) were obtained for 28, 27 and 30 individuals, respectively. All of the specimens had at least one of the fragments sequenced, but only the 25 individuals that presented sequences for the three fragments were considered in the network and AMOVA with no gaps allowed. However, individuals with missing $C O I$ or $C y t-b$ sequences were included in the molecular dating analysis.

\section{Genetic structure}

The haplotype network revealed 20 mitochondrial haplotypes grouped in seven geographic clusters separated by a large number of mutations (Figure 2). These clusters correspond to haplotypes found in: Ucayali and Acre (UA cluster), Rondônia (RO cluster) and Porto de Moz and Vitória do Xingu (PV cluster), all located on the right bank of the Amazon River; Loreto and Santa Isabel do Rio Negro (LS cluster) and Manaus, Oriximiná, Suriname and French Guiana (MOSF cluster), all located on the left bank of the Amazon River; Colombia to the west of the Andes (CWA cluster); and Maranhão, Pernambuco and Rio Grande do Norte in northeastern Brazil (NB cluster). There were neither predominant nor shared haplotypes between clusters showing a marked genetic structure according to spatial distribution. The largest amount of mutation steps (> 138) occurred between two groups of haplotype clusters that co-

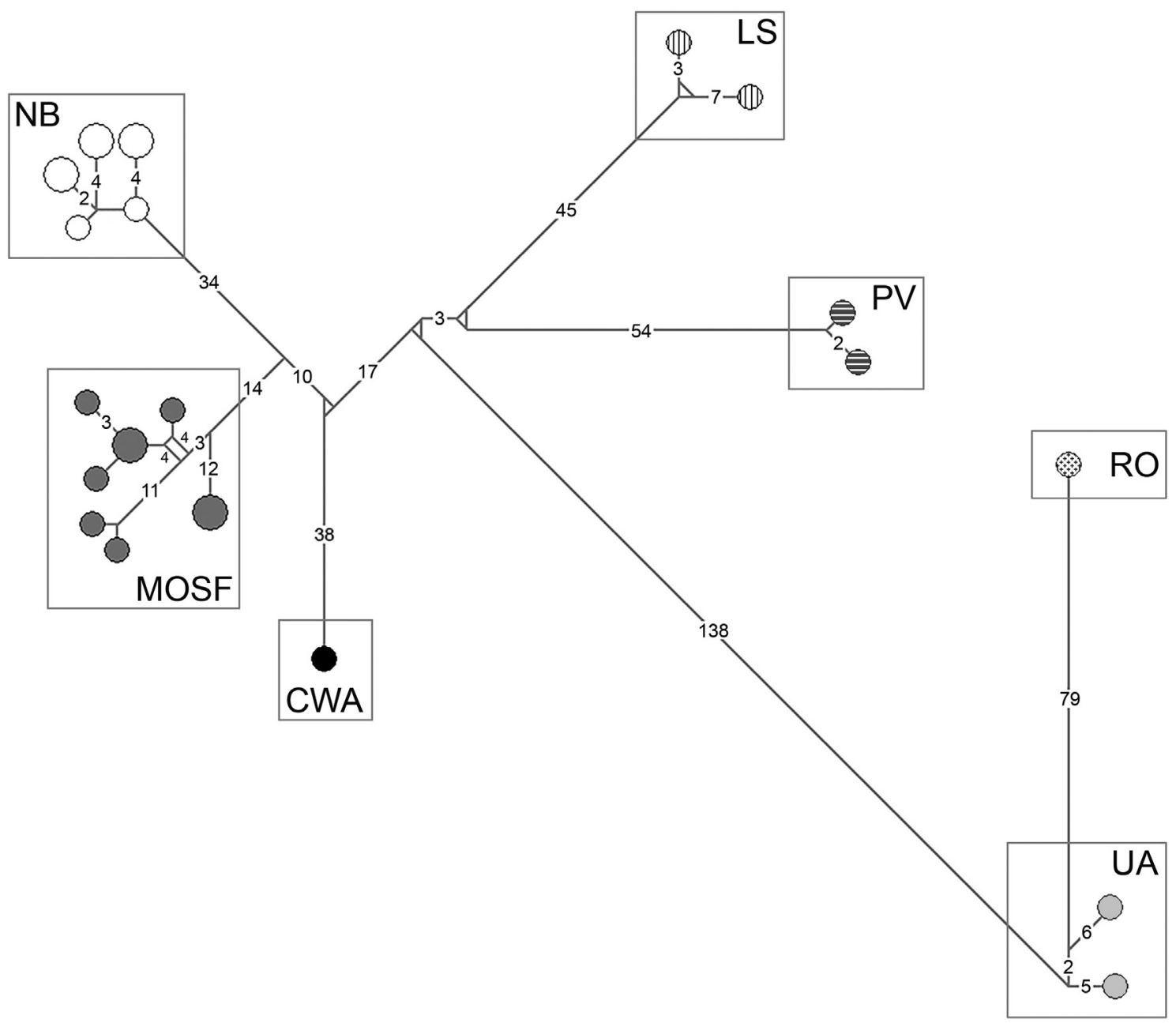

Figure 2 - Mitochondrial haplotype network showing seven geographic clusters. The network was constructed with concatenated mitochondrial data using the median-joining algorithm. Circle sizes are proportional to frequencies, and mutation step numbers greater than one are indicated on the lines. $\mathrm{UA}=$ Ucayali; RO = Rondônia; LS = Loreto and Santa Isabel do Rio Negro; PV = Porto de Moz and Vitória do Xingu; CWA = Colombia to the west of the Andes; MOSF = Manaus, Oriximiná, Suriname and French Guiana; NB = northeastern Brazil. 
incided with a south-north division of the species distribution: the UA and RO clusters to the south and all the others to the north. Besides, the RO and CWA clusters comprised only one individual each and, thus, were excluded from the following AMOVA.

The AMOVA results for the five clusters analyzed (UA, LS, PV, MOSF and NB) reinforced the genetic structure exhibited in the haplotype network with a $\varphi_{\mathrm{ST}}$ estimate of $0.904(P=0.00000)$ indicating that most part of the genetic diversity of $C$. didactylus is due to differences between the clusters.

\section{Molecular dating}

The MCC tree obtained in the molecular dating analysis (Figure 3) showed a topology congruent with previous molecular phylogenetic studies involving xenarthran genera (Delsuc et al., 2001, 2002, 2003, 2012; Möller-Krull et al., 2007). In addition, it revealed two major monophyletic clades comprising seven mitochondrial lineages within Cyclopes didactylus, all fully supported, that corresponded to the south-north division of the species range and the seven geographic clusters found on the haplotype network, respectively. The phylogenetic relations between these mtDNA lineages were also supported by high posterior values $(\geq 0.82)$ in all branches except the one grouping MOSF and NB as sister clusters (0.67). The individuals from Loreto (CD017), Acre (CD030), Amapá (CD016) and Manaus (CD032), and Piauí (CD027, CD028 and CD029), which were not included in the haplotype network, grouped in the phylogeny within the LS, UA, MOSF and NB lineages, respectively, according to our expectations. Furthermore, our time estimate (Figure 3 and Table 1) is compatible with previous molecular dating studies (Delsuc et al., 2004, 2012; Gibb et al., 2016). The only notable difference regards Myrmecophagidae and Tamandua nodes. For these nodes, the newly estimated ages, 19 and 2 mya, respectively, are considerably older than previous ones, 13-10 and 1 mya, respectively (Delsuc et al., 2004, 2012; Gibb et al., 2016). Such differences are expected with a denser taxon sampling as reported by Gibb et al. (2016) for Folivora, Dasypodinae, Euphractinae and Tolypeutinae nodes.

\section{Discussion}

\section{Phylogeographic patterns in Cyclopes didactylus}

The mtDNA sequences of the silky anteater analyzed here revealed the existence of two lineages (UA and RO) located in the southern part of the species' current range and five lineages (LS, PV, CWA, MOSF and NB) present in its northern part. This pattern of south-north division is supported by the largest amount of mutation steps (> 138) found between those haplotype clusters in the network (Figure 2) and by the oldest divergence (13.45 mya) within C. didactylus in the dated phylogeny (Figure 3 and Table 1). Even though we could not determine a clear geographic boundary for this major genetic division, it indicates an ini-

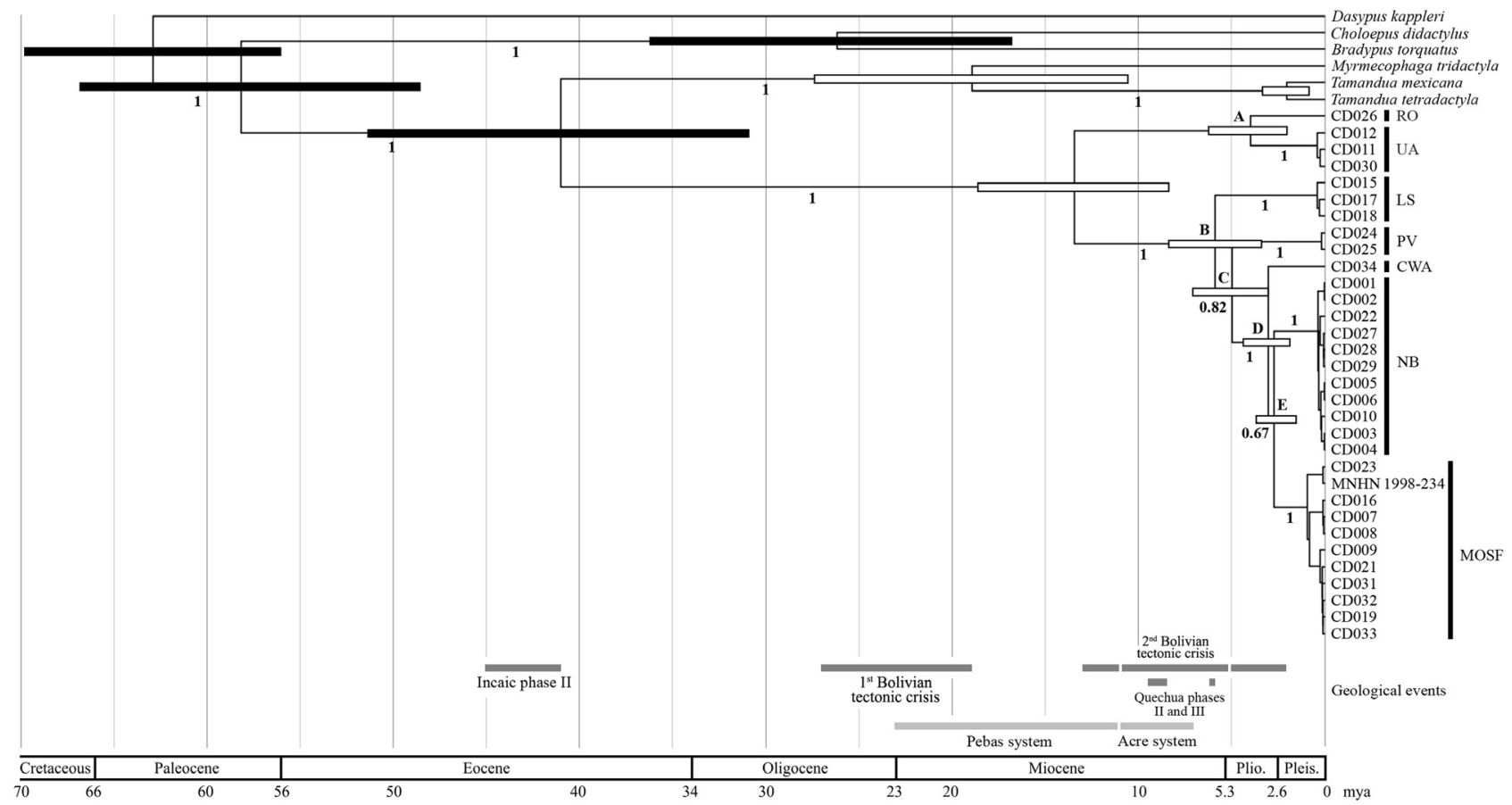

Figure 3 - Molecular timescale for Cyclopes didactylus and other xenarthran nodes inferred in this study. Node ages were obtained using a relaxed clock model under the reversible-jump based substitution model, allowing gamma rate heterogeneity and invariant sites, and a birth-death tree prior with soft fossil calibrations. Node bars indicate the $95 \%$ HPD intervals for age estimates in million years ago. Plain black and white node bars indicate constrained and unconstrained nodes, respectively. Divergence dates less than 1 mya are not represented. Letters at nodes refer to Table 1. 
Table 1 - Divergence time estimates for Cyclopes didactylus and other xenarthran nodes inferred in this study. Node ages were obtained using the reversible-jump based substitution model with gamma rate heterogeneity and invariant sites and a relaxed clock model. Mean posterior estimates and $95 \%$ HPD intervals are expressed in million years ago. Divergence dates less than 1 mya are not shown. Letters A - E refer to nodes in Figure 3.

\begin{tabular}{lccc}
\hline Node & Mean & Min. & Max. \\
\hline Xenarthra $^{\text {a }}$ & 62.89 & 55.68 & 69.91 \\
Pilosa $^{\text {a }}$ & 58.15 & 48.46 & 66.96 \\
Folivora $^{\text {a }}$ & 26.18 & 16.81 & 36.13 \\
Vermilingua a $^{\text {M }}$ & 40.99 & 30.9 & 51.3 \\
Myrmecophagidae $_{\text {T. mexicana / T. tetradactyla }}$ & 18.92 & 10.64 & 27.51 \\
Cyclopes didactylus & 2.06 & 0.87 & 3.46 \\
A & 13.45 & 8.34 & 18.82 \\
B & 3.97 & 1.94 & 6.27 \\
C & 5.88 & 3.43 & 8.42 \\
D & 4.97 & 3.0 & 7.08 \\
E & 3.05 & 1.78 & 4.48 \\
\hline
\end{tabular}

${ }^{a}$ fossil calibrated nodes

tial diversification close to the Andes. In addition, the UA, RO and PV lineages seem to be geographically isolated from the LS and MOSF lineages by the Solimões/Amazon Rivers. Moreover, there is a phylogeographic break between LS and MOSF lineages, which may be represented by the Negro River acting as a barrier. Although the Solimões/Amazon and Negro Rivers apparently limit the range of some of the mtDNA lineages of $C$. didactylus, they may not be historical boundaries or causal mechanisms for the divergences.

The CWA lineage is isolated from the Amazonian silky anteaters by the eastern Andean Cordillera in northern Colombia. This lineage was probably already there when the eastern Andes was no more than $40 \%$ of its modern elevation (Gregory-Wodzicki, 2000). Thus, the mountain uplift in that region between 5 and 2 mya (Lundberg et al., 1998; Gregory-Wodzicki, 2000; Hoorn et al., 2010) may be likely the vicariant event responsible for its isolation and differentiation at ca. 3.05 mya. This pattern of west and east divergence in the Andean region is also observed for the sloths B. variegatus and C. hoffmanni (Moraes-Barros and Arteaga, 2015), woodcreepers of the genus Dendrocincla (Weir and Price, 2011) howler monkeys (Alouatta; Cortés-Ortiz et al., 2003), and bats (Redondo et al., 2008).

The haplotypes from the Brazilian Atlantic forest formed a monophyletic group (NB) with the haplotypes from Maranhão and Piauí suggesting a past connection between the Amazon and the Atlantic forests, at least 2.72 mya, when this lineage diverged. Such connection through northeastern Brazil was also suggested for phylogeographic patterns of woodcreeper species endemic to the Atlantic forest (Cabanne et al., 2008; Weir and Price, 2011) and small mammals (Costa, 2003).

From an evolutionary standpoint, the first lineages of silky anteater to diverge (UA-RO and LS) are found in Western Amazonia, and those diverging more recently are found in Eastern Amazonia (PV and MOSF) and the Atlantic forest (NB), or to the west of the Andes in northwestern South America (CWA). This suggests that $C$. didactylus mitochondrial lineages originated in Western Amazonia, somewhere around Peru.

The large amount of mutation steps separating groups of exclusive haplotypes, which corresponded to monophyletic lineages, and the high degree of genetic differentiation $\left(\varphi_{\mathrm{ST}}=0.904\right)$ between at least five of these groups (UA, LS, PV, MOSF and NB), not only shows that $C$. didactylus is genetically and geographically structured, but also that the populations and their mtDNA lineages are very distinct from each other. However, such remarkable genetic structure disagrees with the proposed subspecies division (Wetzel, 1982; Gardner, 2007), where five of them should be represented in our sampling based on their ranges (Hayssen et al., 2012): C. d. catellus (Rondônia/Brazil), C. d. didactylus (Pernambuco-Rio Grande do Norte/Brazil, Suriname and French Guiana), C. d. dorsalis (Colombia), C. d. ida (Ucayali-Loreto/Peru and Acre-Amazonas/Brazil) and $\quad C . \quad d$. melini (Amazonas-Pará-AmapáMaranhão/Brazil). This raises the need to review the current taxonomic status of Cyclopes didactylus (F. R. Miranda et al., in prep.).

\section{Molecular dating of xenarthran lineages}

Our age estimates corroborate the general findings about xenarthrans, which first appeared in the early Paleocene and subsequently underwent an impressive radiation during the Tertiary, when South America was isolated from other landmasses (Delsuc et al., 2004). Major tectonic and climatic events were already associated with the diversification of sloths, anteaters and armadillos (Delsuc et al., 2004; Moraes-Barros and Arteaga, 2015; Gibb et al., 2016). However, a few discrepancies regarding previous time estimates (Delsuc et al., 2004, 2012; Gibb et al., 2016) were observed for divergences within Myrmecophagidae, and can be explained by the increased number of Cyclopes didactylus samples used in our analysis. As previously said, this is expected with a denser taxon sampling (Gibb et al., 2016), which affects the coalescence between myrmecophagid species causing them to become older: around 19 mya compared to 13-10 mya (Delsuc et al., 2004, 2012; Gibb et al., 2016) for the divergence between Myrmecophaga and Tamandua, and around 2 mya compared to 1 mya (Gibb et al., 2016) for the separation between $T$. tetradactyla and $T$. mexicana. The myrmecophagid splits are discussed below.

The divergence between Myrmecophaga tridactyla and Tamandua at ca. 19 mya correlates well with the end of 
the first Bolivian tectonic crisis in the early Miocene (27-19 mya; Sempere et al., 1990). This period also coincides with a global warm phase, which culminated in the Middle Miocene Climatic Optimum (Zachos et al., 2001). Such events were already associated with the diversification of modern sloths lineages and Tolypeutinae armadillos (Delsuc et al., 2004).

The age for separation between T. mexicana and $T$. tetradactyla at ca. 2 mya matches up with the ending of the final uplift of the Northern Andes (5-2 mya; Lundberg et al., 1998; Hoorn et al., 2010). Thus, this geologic event may explain the vicariance seen between the two Tamandua species, as suggested by Gibb et al. (2016).

\section{Insights on the evolutionary history of Cyclopes didactylus}

The split of lineages separating Cyclopes and the other anteaters genera occurred around 41 mya, in the middle Eocene, shortly after a large episode of mountain uplift in the Andes of Peru known as "Incaic tectonic phase II", estimated between 45 and 41 mya (Noble et al., 1990; Lundberg et al., 1998; Delsuc et al., 2004; Antonelli et al., 2009). After that, an interval of more than 27 million years preceded the start of the silky anteater diversification.

The first divergence within Cyclopes didactylus, at ca. 13.5 mya, separated two major monophyletic clades: one that would give rise to the UA and RO lineages, in the south of the species current distribution; and other that would originate all the other lineages, in the north. This connects with the start of an intensified uplift in the Central and Northern Andes between 13 and 11 mya (Antonelli et al., 2009; Hoorn et al., 2010) and with the final stages of the so-called "Pebas" system (Hoorn et al., 2010). From 23 to 11 mya, this system transformed most of Western Amazonia in a large wetland of shallow lakes and swamps that fragmented the preexisting rainforest (Antonelli et al., 2009; Hoorn et al., 2010). For an arboreal species with low dispersal abilities like the silky anteater, a fragmented forest habitat could promote isolation for a period of time sufficient for the divergence between the southern and northern clades.

From 11 to 7 mya, parallel to a new period of rapid Andean mountain building sometimes termed "Quechua phases II and III" (Mégard, 1984; Noble et al., 1990; Antonelli et al., 2009), the lacustrine Pebas system changed into a fluvial or fluviotidal "Acre" system (Hoorn et al., 2010). The return of forested habitats shortly after the demise of Western Amazonian wetlands (Hoorn et al., 2010) may have triggered the divergence of the mitochondrial lineage found in Loreto and Santa Isabel do Rio Negro (LS) at ca. 6 mya. Similarly, plant diversity also increased between 7 and 5 mya, following the return of terrestrial conditions (Hoorn et al., 2010).

The subsequent divergence between PV and the other mitochondrial lineages at around 5 mya, cannot be ex- plained by vicariance and, thus, may have been prompted by other factors such as biotic interactions.

The haplotypes found in Ucayali and Acre (UA) and the one found in Rondônia (RO) became separated mitochondrial lineages around 4 mya. This period followed the end of the second major Bolivian tectonic crisis in the late Miocene (11-5 mya; Marshall and Sempere, 1991).

In the case of the Colombian haplotype (CWA), which is separated from the other South American lineages by the Northern Andes, the estimated divergence at ca. 3 mya correlates well, as previously said, with the end of the final uplift of the Eastern Cordillera in that region (Lundberg et al., 1998; Gregory-Wodzicki, 2000; Hoorn et al., 2010), as observed for the vicariance between the two Tamandua species.

Finally, the mitochondrial lineages found in northeastern Amazonia (MOSF) and northeastern Brazil (NB) diverged at 2.7 mya. The fact that the individuals from Maranhão coastline forest and Piauí mangrove, both areas within the main distribution of the species in South America, group together with the small population of the Atlantic forest suggests that these distribution areas were actually connected. In addition, the order of the divergences within the NB lineage is congruent with a dispersal event starting from Maranhão and crossing all the way to the northeastern Atlantic forest. A potential cause for this dispersal of $C$. didactylus could be associated with the beginning of the Pleistocene glacial cycles at around 2.6 mya (Hoorn et al., 2010; Antonelli and Sanmartín, 2011) and a likely connection between Amazon and Atlantic forests (Costa, 2003; Auler et al., 2004; Wang et al., 2004; Cabanne et al., 2008; Batalha-Filho et al., 2013).

The small number of samples from CWA and PV lineages included in our molecular dating analysis, and sampling gaps like the one we have in southern Amazonia, between Purus and Tapajós rivers, hinders detailed interpretations on how dispersal events occurred and increases the possibility of unidentified lineages that would likely change the topology of the phylogeny and, consequentially, alter the sequence and/or age of the splits. We recognize the difficulty in obtaining samples of this elusive species, but future studies will need a denser and more extensive sampling to overcome these problems.

In summary, our results show a strong and complex genetic structure for the silky anteater population distribution, and confirm the antiquity of its lineage, which separated from the other vermilinguas as early as the middle Eocene (41 mya) and began to diversify in the late-middle Miocene (13.5 mya) in southwestern Amazonia. Moreover, we emphasize the importance of the tectonic and climatic changes that took place in South America during the Tertiary and Quaternary for the species diversification and population dynamics. 


\section{Acknowledgments}

This work was supported by FAPEMIG, CNPq and Fundação O Boticário from Brazil. We would like to thank technical help on some experiments to Bruno Moreira, Maria Clara Pardini, Bárbara Chaves, and Gisele P. M. Dantas. R.T.F.C. received an undergraduate studentship from CNPq, F.R.M. has a Ph.D. fellowship from CAPES, C.C.L. received a technical fellowship from CNPq, M.A.A.S. has a Ph.D. fellowship from FAPEMIG, and F.R.S has a research fellowship from CNPq.

\section{References}

Aguiar JM and Fonseca GAB (2008) Conservation status of the Xenarthra. In: Vizcaíno SF and Loughry WJ (eds) The Biology of the Xenarthra. University Press of Florida, Gainesville, pp 215-231.

Antonelli A and Sanmartín I (2011) Why are there so many plant species in the Neotropics? Taxon 60:403-414.

Antonelli A, Nylander JAA, Persson C and Sanmartín I (2009) Tracing the impact of the Andean uplift on neotropical plant evolution. Proc Natl Acad Sci U S A 106:9749-9754.

Auler AS, Wang X, Edwards RL, Cheng H, Cristalli PS, Smart PL and Richards DA (2004) Quaternary ecological and geomorphic changes associated with rainfall events in presently semi-arid northeastern Brazil. J Quaternary Sci 19:693-701.

Bacon CD, Silvestro D, Jaramillo C, Smith BT, Chakrabarty P and Antonelli A (2015) Biological evidence supports an early and complex emergence of the Isthmus of Panama. Proc Natl Acad Sci U S A 112:6110-6115.

Bandelt H, Forster P and Röhl A (1999) Median-joining networks for inferring intraspecific phylogenies. Mol Biol Evol 16:37-48.

Batalha-Filho H, Fjeldså J, Fabre PH and Miyaki CY (2013) Connections between the Atlantic and the Amazonian forest avifaunas represent distinct historical events. J Ornithol 154:41-50.

Bouckaert R, Alvarado-Mora M and Pinho JRR (2013) Evolutionary rates and HBV: Issues of rate estimation with Bayesian molecular methods. Antivir Ther 18:497-503.

Bouckaert R, Heled J, Kühnert D, Vaughan T, Wu C, Xie D, Suchard MA, Rambaut A and Drummond AJ (2014) BEAST 2: A software platform for bayesian evolutionary analysis. PLoS Comput Biol 10:e1003537.

Cabanne GS, d'Horta FM, Sari EHR, Santos FR and Miyaki CY (2008) Nuclear and mitochondrial phylogeography of the Atlantic forest endemic Xiphorhynchus fuscus (Aves: Dendrocolaptidae): Biogeography and systematics implications. Mol Phylogenet Evol 49:760-773.

Cortés-Ortiz L, Bermingham E, Rico C, Rodríguez-Luna E, Sampaio I and Ruiz-García M (2003) Molecular systematics and biogeography of the Neotropical monkey genus, Alouatta. Mol Phylogenet Evol 26:64-81.

Costa LP (2003) The historical bridge between the Amazon and the Atlantic forest of Brazil: A study of molecular phylogeography with small mammals. J Biogeogr 30:71-86.

Delsuc F, Catzeflis FM, Stanhope MJ and Douzery EJP (2001) The evolution of armadillos, anteaters and sloths depicted by nuclear and mitochondrial phylogenies: Implications for the status of the enigmatic fossil Eurotamandua. Proc R Soc Lond B 268:1605-1615.

Delsuc F, Scally M, Madsen O, Stanhope MJ, de Jong WW, Catzeflis FM, Springer MS and Douzery EJP (2002) Molecular phylogeny of living xenarthrans and the impact of character and taxon sampling on the placental tree rooting. Mol Biol Evol 19:1656-1671.

Delsuc F, Stanhope MJ and Douzery EJP (2003) Molecular systematics of armadillos (Xenarthra, Dasypodidae): Contribution of maximum likelihood and Bayesian analyses of mitochondrial and nuclear genes. Mol Phylogenet Evol 28:261-275.

Delsuc F, Vizcaíno SF and Douzery EJP (2004) Influence of Tertiary paleoenvironmental changes on the diversification of South American mammals: A relaxed molecular clock study within xenarthrans. BMC Evol Biol 4:11.

Delsuc F, Superina M, Tilak M, Douzery EJP and Hassanin A (2012) Molecular phylogenetics unveils the ancient evolutionary origins of the enigmatic fairy armadillos. Mol Phylogenet Evol 62:673-680.

Douzery E and Randi E (1997) The mitochondrial control region of Cervidae: Evolutionary patterns and phylogenetic content. Mol Biol Evol 14:1154-1166.

Ewing B and Green P (1998) Base-calling of automated sequencer traces using Phred. II. Error probabilities. Genome Res 8:186-194.

Ewing B, Hillier L, Wendl MC and Green P (1998) Base-calling of automated sequencer traces using Phred. I. Accuracy assessment. Genome Res 8:175-185.

Excoffier L and Lischer HEL (2010) Arlequin suite ver 3.5: A new series of programs to perform population genetics analyses under Linux and Windows. Mol Ecol Resour 10:564-567.

Excoffier L, Smouse PE and Quattro JM (1992) Analysis of molecular variance inferred from metric distances among DNA haplotypes: Application to human mitochondrial DNA restriction data. Genetics 131:479-491.

Folmer O, Black M, Hoeh W, Lutz R and Vrijenhoek R (1994) DNA primers for amplification of mitochondrial cytochrome c oxidase subunit I from diverse metazoan invertebrates. Mol Mar Biol Biotechnol 3:294-299.

Gardner AL (2007) Order Pilosa: Suborder Vermilingua: Family Cyclopedidae. In: Gardner AL (ed) Mammals of South America Volume 1: Marsupials, Xenarthrans, Shrews, and Bats. University of Chicago Press, Chicago, pp 169-171.

Gaudin TJ and Branham DG (1998) The phylogeny of the Myrmecophagidae (Mammalia, Xenarthra, Vermilingua) and the relationship of Eurotamandua to the Vermilingua. J Mamm Evol 5:237-265.

Gibb GC, Condamine FL, Kuch M, Enk J, Moraes-Barros N, Superina M, Poinar HN and Delsuc F (2016) Shotgun mitogenomics provides a reference phylogenetic framework and timescale for living xenarthrans. Mol Biol Evol 33:621-642.

Gordon D, Abajian C and Green P (1998) Consed: A graphical tool for sequence finishing. Genome Res 8:195-202.

Gregory-Wodzicki KM (2000) Uplift history of the Central and Northern Andes: A review. Geol Soc Am Bull 112:1091-1105.

Hayssen V, Miranda F and Pasch B (2012) Cyclopes didactylus (Pilosa: Cyclopedidae). Mamm Species 44:51-58. 
Hirschfeld SE (1976) A new fossil anteater (Edentata, Mammalia) from Colombia, S.A. and evolution of the Vermilingua. J Paleontol 50:419-432.

Hoorn C (1993) Marine incursions and the influence of Andean tectonics on the Miocene depositional history of northwestern Amazonia: Results of a palynostratigraphic study. Palaeogeogr Palaeoclimatol Palaeoecol 105:267-309.

Hoorn C, Wesselingh FP, Steege HT, Bermudez MA, Mora A, Sevink J, Sanmartín I, Sanchez-Meseguer A, Anderson CL, Figueiredo JP, et al. (2010) Amazonia through time: Andean uplift, climate change, landscape evolution, and biodiversity. Science 330:927-931.

Huchon D, Delsuc F, Catzeflis FM and Douzery EJP (2001) Armadillos exhibit less genetic polymorphism in North America than in South America: Nuclear and mitochondrial data confirm a founder effect in Dasypus novemcinctus (Xenarthra). Mol Ecol 8:1743-1748.

Kumar S, Stecher G and Tamura K (2016) MEGA7: Molecular Evolutionary Genetics Analysis version 7.0 for bigger datasets. Mol Biol Evol 33:1870-1874.

Lovejoy NR, Albert JS and Crampton WGR (2006) Miocene marine incursions and marine/freshwater transitions: Evidence from neotropical fishes. J South Am Earth Sci 21:5-13.

Lundberg JG, Marshall LG, Guerrero J, Brian H, Malabarba MCSL and Wesselingh F (1998) The stage for neotropical fish diversification: A history of tropical South American rivers. In: Malabarba LR, Reis RE, Vari RP, Lucena ZM and Lucena CAS (eds) Phylogeny and Classification of Neotropical Fishes. Edipucrs, Porto Alegre, pp 13-48.

Marshall LG and Sempere T (1991) The Eocene to Pleistocene vertebrates of Bolivia and their stratigraphic context: A review. In: Suarez-Soruco R (ed) Fosiles y Facies de Bolivia Volume 1: Vertebrados. Rev Téc YPFB 12:631-652.

McDonald HG, Vizcaíno SF and Bargo MS (2008) Skeletal anatomy and the fossil history of the Vermilingua. In: Vizcaíno SF and Loughry WJ (eds) The Biology of the Xenarthra. University Press of Florida, Gainesville, pp 257-268.

Mégard F (1984) The Andean orogenic period and its major structures in central and northern Peru. J Geol Soc London 141:893-900.

Meredith RW, Janecka JE, Gatesy J, Ryder OA, Fisher CA, Teeling EC, Goodbla A, Eizirik E, Simão TLL, Stadler T, et al. (2011) Impacts of the Cretaceous terrestrial revolution and $\mathrm{KPg}$ extinction on mammal diversification. Science 334:521-524.

Miller MA, Pfeiffer W and Schwartz T (2010) Creating the CIPRES Science Gateway for inference of large phylogenetic trees. Proceedings of the Gateway Computing Environments Workshop, New Orleans, pp 1-8.

Miranda F and Superina M (2010) New distribution records of the silky anteater Cyclopes didactylus (Pilosa, Cyclopedidae) in coastal Northeastern Brazil. Mastozool Neotrop 17:381-384.

Möller-Krull M, Delsuc F, Churakov G, Marker C, Superina M, Brosius J, Douzery EJP and Schmitz J (2007) Retroposed elements and their flanking regions resolve the evolutionary history of xenarthran mammals (armadillos, anteaters, and sloths). Mol Biol Evol 24:2573-2582.

Montes C, Cardona A, Jaramillo C, Pardo A, Silva JC, Valencia V, Ayala C, Pérez-Angel LC, Rodriguez-Parra LA, Ramirez
$\mathrm{V}$, et al. (2015) Middle Miocene closure of the Central American Seaway. Science 348:226-229.

Montgomery GG (1985) Movements, foraging and food habits of the four extant species of neotropical vermilinguas (Mammalia; Myrmecophagidae). In: Montgomery GG (ed) The Evolution and Ecology of Armadillos, Sloths, and Vermilinguas. Smithsonian Institution Press, Washington, pp 365-378.

Moraes-Barros N and Arteaga MC (2015) Genetic diversity in Xenarthra and its relevance to patterns of Neotropical biodiversity. J Mammal 96:690-702.

Noble DC, McKee EH, Mourier T and Mégard F (1990) Cenozoic stratigraphy, magmatic activity, compressive deformation, and uplift in northern Peru. Geol Soc Am Bull 102:1105-1113

Oliveira PE, Barreto AMF and Suguio K (1999) Late Pleistocene/Holocene climatic and vegetational history of the Brazilian caatinga: The fossil dunes of the middle São Francisco River. Palaeogeogr Palaeoclimatol Palaeoecol 152:319-337.

Ortiz-Jaureguizar E and Cladera GA (2006) Paleoenvironmental evolution of southern South America during the Cenozoic. J Arid Environ 66:498-532.

Patterson B and Pascual R (1972) The fossil mammal fauna of South America. In: Keast A, Erk FC and Glass B (eds) Evolution, Mammals and Southern Continents. S.U.N.Y. Press, Albany, pp 247-309.

Redondo RA, Brina LP, Silva RF, Ditchfield AD and Santos FR (2008) Molecular systematics of the genus Artibeus (Chiroptera: Phyllostomidae). Mol Phylogenet Evol 49:44-58.

Sambrook J and Russell DW (2001) Molecular Cloning: A Laboratory Manual. 3rd edition. Cold Spring Harbor Laboratory Press, New York.

Santos Júnior JE, Santos FR and Silveira FA (2015) Hitting an unintended target: Phylogeography of Bombus brasiliensis Lepeletier, 1836 and the first new Brazilian bumblebee species in a century (Hymenoptera: Apidae). PLoS One 10:e0125847.

Sempere T, Hérail G, Oller J and Bonhomme MG (1990) Late Oligocene-early Miocene major tectonic crisis and related basins in Bolivia. Geology 18:946-949.

Sempere T, Marshall LG, Rivano S and Godoy E (1994) Late Oligocene-Early Miocene compressional tectosedimentary episode and associated land-mammal faunas in the Andes of central Chile and adjacent Argentina (32-37's). Tectonophysics 229:251-264.

Superina M, Miranda FR and Abba AM (2010) The 2010 anteater red list assessment. Edentata 12:96-114.

Wang X, Auler AS, Edwards RL, Cheng H, Cristalli PS, Smart PL, Richards DA and Shen CC (2004) Wet periods in northeastern Brazil over the past $210 \mathrm{kyr}$ linked to distant climate anomalies. Nature 432:740-743.

Weir JT and Price M (2011) Andean uplift promotes lowland speciation through vicariance and dispersal in Dendrocincla woodcreepers. Mol Ecol 20:4550-4563.

Wetzel RM (1982) Systematics, distribution, ecology, and conservation of South American edentates. In: Mares MA and Genoways HH (eds) The Pymatuning Symposia in Ecology Volume 6: Mammalian Biology in South America. University of Pittsburgh, Pittsburgh, pp 345-375. 
Wetzel RM (1985) The identification and distribution of recent Xenarthra (= Edentata). In: Montgomery GG (ed) The Evolution and Ecology of Armadillos, Sloths, and Vermilinguas. Smithsonian Institution Press, Washington, pp 5-21.

Yang Z and Rannala B (2006) Bayesian estimation of species divergence times under a molecular clock using multiple fossil calibrations with soft bounds. Mol Biol Evol 23:212-226.

Zachos J, Pagani M, Sloan L, Thomas E and Billups K (2001) Trends, rhythms, and aberrations in global climate $65 \mathrm{Ma}$ to present. Science 292:686-693.

\section{Internet Resources}

Green P (1994-1999) Phrap v. 0.990319, http//www.phrap.org (July 11, 2012).
Fluxus Technology Ltd (1999-2016) Network v. 5, http://www.fluxus-engineering.com (August 03, 2016).

Rambaut A, Suchard MA, Xie D and Drummond AJ (2014) Tracer v. 1.6, http://beast.bio.ed.ac.uk/Tracer (November 29, 2015).

\section{Supplementary material}

The following online material is available for this article: Table S1 - Detailed list of samples and respective localities. Table S2 - List of fossils used as soft calibration constraints in the molecular dating analysis.

Associate Editor: Louis Bernard Klaczko

License information: This is an open-access article distributed under the terms of the Creative Commons Attribution License (type CC-BY), which permits unrestricted use, distribution and reproduction in any medium, provided the original article is properly cited. 